MICHAŁ A. MICHALSKI

$\stackrel{\circ}{||}$

\title{
Z POWROTEM DO OIKOS NOMOS, Z POWROTEM DO RZECZYWISTOŚCI... MATERIALISTYCZNA TRANSFORMACJA KULTURY ZACHODU A ZWROT SPOŁECZNO-KULTUROWY W EKONOMII
}

ABSTRACT. Michał A. Michalski, Z powrotem do oikos nomos, z powrotem do rzeczywistości... Materialistyczna transformacja kultury Zachodu a zwrot społeczno-kulturowy wekonomii [Back to oikos nomos, Back to Reality... Materialistic Transformation of the Western Culture and Socio-Cultural Turn in Economics] edited by W. Banach, M.A. Michalski, J. Sójka, "Człowiek i Społeczeństwo" vol. XLVI: Między Chinami a Zachodem. Pytanie o źródła chińskiego sukcesu gospodarczego [Between China and the West. An inquiry into the sources of the Chinese economic miracle], Poznań 2018, pp. 203-215, Adam Mickiewicz University. Faculty of Social Sciences Press. ISSN 0239-3271.

In this article, I put forward the thesis that the current socio-economic situation is to a large extent caused by the changes that have taken place in Western culture over the last few centuries. This means that, to a large extent, the considerations discussed here refer to the perspective of economic culture. The reason for undertaking this issue is paradoxical situation of socio-economic stagnation and recourse in the contemporary West which has achieved unprecedented level of social, scientific and technological development.

In order to explain this problem, the article proposes to analyse the process of materialisation of the Western culture which means that the materialistic point of view colonizes at the same time capitalist and socialist concepts and policies. It becomes evident e.g. in the prioritizing economic policy and economic development as the universal solution to all social challenges and marginalizing metaphysical aspects of human and social existence.

According to the conclusion of the article it is necessary to understand the influence of materialistic point of view in order to rethink and analyse contemporary shape of Western culture and condition of Western civilization. 
Michał A. Michalski, Uniwersytet im. Adama Mickiewicza w Poznaniu, Wydział Nauk Społecznych, Instytut Kulturoznawstwa, Zakład Etyki Gospodarczej, ul. Szamarzewskiego 89a, 60-568 Poznań, e-mail:mmichal@amu.edu.pl

\section{Wprowadzenie}

W kontekście sytuacji społeczno-gospodarczej ostatnich lat na plan pierwszy wysuwa się paradoks, który polega na tym, że z jednej strony Zachód dysponuje obecnie tak dużym potencjałem gospodarczym z jego ogromnymi możliwościami technologicznymi i organizacyjnymi, a z drugiej strony wiele wskazuje na to, że nie przekłada się to na wyraźny rozwój cywilizacyjny rozumiany w skrócie nie tylko jako dobrobyt, ale także jako dobrostan. Innymi słowy, okazuje się, że warto z uwagą spojrzeć na koncepcję Roberta E. Lane'a, autora książki The Loss of Happiness in Market Democracies, który już tytułem swej pracy zwraca uwagę na paradoksalną sytuację naszej cywilizacji, która z jednej strony osiągnęła wysoki poziom rozwoju materialnego i technicznego, a z drugiej - nie staje się przez to szczęśliwsza ${ }^{1}$. Mówiąc jeszcze dosadniej, można powiedzieć, że starzeje się i wymiera. Problem ten jest, jak się zdaje, coraz wyraźniej dostrzegany, jednak wciąż środki zaradcze są w większym stopniu nakierowane na radzenie sobie z symptomami, a w mniejszym na dogłębną diagnozę przyczyn takiego stanu rzeczy. Oznacza to, że próbuje się przede wszystkim poszukiwać rozwiązań o charakterze ekonomicznym, dzięki którym ożywieniu winna ulec gospodarka, a to ma wystarczyć, by społeczeństwo wróciło na wcześniejsze tory zadowolenia i dobrobytu. Wiele wszakże wskazuje na to, że w przypadku cywilizacji zachodniej mamy w ostatnich dekadach do czynienia z kryzysem znacznie głębszym i bardziej złożonym niż tylko tymczasowe osłabienie koniunktury, któremu można szybko i łatwo zaradzić.

W niniejszym artykule stawiam tezę, że w dużej mierze obecna sytuacja spowodowana jest przemianami, jakie w kulturze Zachodu dokonały się na przestrzeni ostatnich kilku stuleci. Oznacza to, że rozważania tu podjęte nawiązują przede wszystkim do perspektywy kulturowych badań nad gospodarowaniem, których głównym przedmiotem zainteresowania jest kultura

${ }^{1}$ Por. R.E. Lane, The Loss of Happiness in Market Democracies, Yale University Press, New Haven 2000. 
gospodarcza rozumiana jako „społeczno-kulturowy kontekst aktywności gospodarczej i funkcjonowanie instytucji gospodarczych”2.

Zwracając uwagę na znaczenie kultury, należy także wspomnieć o jakże ważnym tego aspekcie, tj. kwestii zmiany kulturowej, z którą mamy niewątpliwie do czynienia na Zachodzie w sposób szczególnie dostrzegalny w ostatnich dekadach. Jak stwierdza Fareed Zakaria,

kultura jest ważna, niezwykle ważna. Może się jednak zmienić. Kultury są złożone. W danym momencie niektóre ich cechy wysunięte zostają na pierwszy plan i zdają się niepodważalne. A potem polityka i ekonomia ulegają przemianom, a wówczas cechy te tracą na znaczeniu, robiąc miejsce innym ${ }^{3}$.

W celu bardziej szczegółowego przedstawienia postawionej tezy w dalszych rozważaniach zostanie przeanalizowany trop wskazujący na to, że na skutek różnych przemian - które zostaną przywołane - w kulturze Zachodu, a więc i w jego filozofii społecznej oraz dominującej polityce i teorii ekonomicznej, coraz większą rolę odgrywa obecnie materializm. Innymi słowy, współczesne rozczarowanie niemocą prognostyczną oraz aplikacyjną współczesnej ekonomii oraz nieobecność w niej postulowanego i spodziewanego zwrotu społeczno-kulturowego wynika z tego, że jako cywilizacja nie rozpoznaliśmy jeszcze, iż w obecnym stanie ekonomia - a w szerszym kontekście kultura - jest w znacznej mierze zdominowana przez materializm. W nim należy, moim zdaniem, upatrywać źródeł paradoksów i sprzeczności obecnych w funkcjonowaniu społeczeństw zachodnich drugiej dekady XXI w. W odniesieniu do sfery gospodarczej ważnej inspiracji dla podjętych tu rozważań dostarcza Kenneth E. Boulding, który stwierdza, że „powodzenie instytucji ekonomicznych zależy w znacznym stopniu od charakteru całej kultury, w której są osadzone, a nie od charakteru samych instytucji”4.

2 P.L. Berger, Rewolucja kapitalistyczna, tłum. Z. Simbierowicz, Oficyna Naukowa, Warszawa 1995, s. 20. Warto tu także przywołać sposób rozumienia kultury gospodarczej przez Jacka Kochanowicza, który definiuje ją następująco: „pojęcie kultury ekonomicznej odnosimy [...] do dwu kategorii zjawisk: po pierwsze, do związanych z gospodarką, niekoniecznie uświadamianych dyspozycji ukierunkowujących zachowania jednostek i grup społecznych, a więc do wartości, schematów poznawczych i wzorów postępowania. Po drugie, do wyartykułowanych poglądów na temat tego, jak winno być zorganizowane życie gospodarcze” (J. Kochanowicz, Wprowadzenie, w: J. Kochanowicz, M. Marody (red.), Kultura i gospodarka, Wydawnictwo Naukowe Scholar, Warszawa 2010, s. 18).

${ }^{3}$ F. Zakaria, Koniec hegemonii Ameryki, tłum. S. Kroszczyński, Media Lazar NADIR, Warszawa 2009, ss. 92-93.

${ }^{4}$ K.E. Boulding, Etyka i biznes, w: J. Grosfeld (red.), Ponad ekonomiq, PIW, Warszawa 1985 , s. 70 . 


\section{Pooświeceniowe mapy i bezdroża współczesnego świata}

Problem, o którym mówię, dobrze obrazuje Ernst Friedrich Schumacher, autor m.in. wydanej w Polsce książki Małe jest piękne. Spojrzenie na gospodarkę świata z założeniem, że człowiek coś znaczy, który opisuje swoje doświadczenie z pobytu w Związku Radzieckim w roku 1968, gdy przebywając w Leningradzie, wziął do ręki mapę tego miasta i rozpoczął zwiedzanie. W pewnym momencie zorientował się, że nie jest w stanie określić miejsca swego położenia, przed sobą widział bowiem kilka ogromnych kościołów, których na mapie po prostu nie było 5 .

Historią tą Schumacher rozpoczyna swą książkę Guide for the Perplexed, której tytuł sygnalizuje jej zasadniczą tematykę. Otóż autor Przewodnika dla zakłopotanych (bo tak można by przetłumaczyć ten tytuł) podejmuje w swej pracy problem nieobecności określonych - uznanych czy to za niewłaściwe, niepożądane, czy to za „nienaukowe” - elementów rzeczywistości ujmowanych w dominującym od czasów oświecenia na Zachodzie światopoglądzie. Autorowi nie chodzi tylko i wyłącznie o religię (np. chrześcijaństwo) - zwraca on uwagę również na nieobecność tego, co określić można mianem metafizyki, wraz z którą znika z pola widzenia cały wymiar wertykalny dotyczący kwestii, które pozytywizm oświeceniowy wyrzucił poza nawias wiedzy i poznania w ogóle. Sam Schumacher tak opisuje swoje doświadczenie:

filozoficzne mapy, które dawano mi w szkole i na uniwersytecie, nie tylko - jak mapa Leningradu - nie pokazywały mi „żyjących kościołów”; nie pokazywały także rozległych „nieprawomyślnych” obszarów zarówno teorii, jak i praktyki w medycynie, rolnictwie, psychologii, w naukach społecznych i politycznych, nie wspominając już o sztuce i tzw. zjawiskach tajemnych i paranormalnych, których wzmiankowanie traktowano jako oznakę upośledzenia umysłowego. [...] Nawet w przyrodzie nie dostrzegano niczego artystycznego, chyba że przypadkiem, to znaczy, iż nawet najpiękniejsze zjawiska były w pełni postrzegane - jak nam mówiono - poprzez ich użyteczność dla reprodukcji, jako oddziałujące na selekcję naturalną. W rzeczywistości, poza „muzeami”, cała mapa od prawa do lewa i od góry do dołu sporządzona była w utylitarnych barwach: z trudem coś było ukazane jako rzeczywiste,

${ }^{5}$ E.F. Schumacher, Guide for the Perplexed, Harper Perennial, New York-LondonToronto-Sydney 2004, s. 1. 
o ile nie mogło być potraktowane jako korzystne z punktu widzenia wygody człowieka lub użyteczne w powszechnej bitwie o przetrwanie ${ }^{6}$.

Wydaje mi się, że ten rozdźwięk, o którym wspomina Schumacher, jest podkreślany przez różnych autorów i na różne sposoby. W tym miejscu warto chociażby przywołać Daniela Bella, który w książce Kulturowe sprzeczności kapitalizmu dokonał interesującej analizy kondycji cywilizacji zachodniej, gdzie różne sfery ładu społeczno-kulturowego nakierowane są na realizację odmiennych - i do tego w jakimś wymiarze sprzecznych względem siebie - ideałów.

Stwierdza on w swej pracy, że:

trzy obszary - ekonomia, polityka i kultura - podlegają trzem przeciwstawnym zasadom: wydajności w ekonomii, równości w polityce i samorealizacji (lub samogratyfikacji) - w kulturze. Konflikty w społeczeństwie zachodnim w ciągu ostatnich stu pięćdziesięciu lat miały swe źródło w napięciach wynikających z rozchodzenia się tych trzech obszarów ${ }^{7}$.

Biorąc pod uwagę tę diagnozę, można zasadnie stwierdzić, że wspomniane konflikty nie tylko są wciąż obecne, ale nawet stają się coraz bardziej wyraźne, gdy weźmiemy chociażby pod uwagę z jednej strony coraz bardziej zindywidualizowany styl życia ludzi Zachodu i związane z tym malejące zainteresowanie małżeństwem i rodzicielstwem, od których w znacznym stopniu zależy reprodukcja społeczna, a z drugiej - ambicje społeczeństw zachodnich, aby żyć w świecie dostatnim i bezpiecznym. Dotykamy w ten sposób jednocześnie problemu tożsamości współczesnego człowieka, która wydaje się odzwierciedlać ten zasadniczy rozdźwięk, o którym mówi Bell. W jakimś stopniu pod względem opisowym ciekawe i przydatne okazują się prace Anthony'ego Giddensa, Zygmunta Baumana czy Ulricha Becka. Uważam jednak, że w wymiarze konkretnych propozycji rozwiązania tej sytuacji - która nosi znamiona swoistego kryzysu egzystencjalnego - autorzy ci nie mają nic konkretnego do zaoferowania. Jest tak między innymi dlatego, że w swych analizach - i stanowią oni tego wyraźny przykład - bazują właśnie na takich pooświeceniowych mapach, które w określony, i pod pewnymi względami zredukowany, sposób widzą człowieka i społeczeństwo.

${ }^{6}$ Ibidem, ss. 3-4.

7 D. Bell, Kulturowe sprzeczności kapitalizmu, tłum. S. Amsterdamski, Wydawnictwo Naukowe PWN, Warszawa 1998, s. 32. 
Nie może więc dziwić, że podejmowane w taki właśnie sposób poszukiwanie dróg wyjścia z kryzysu, w jakim znajduje się cywilizacja zachodnia, obecnie nie ma szans powodzenia. Zasadniczym problemem jest właśnie przyjmowanie założeń - m.in. przez wspomnianych powyżej autorów które pomijają istotne z punktu widzenia społeczeństwa aspekty ludzkiej i społecznej egzystencji. I nie chodzi tu o to, że owe „mapy” są nieaktualne, ale o to, że w istocie aktualne nigdy nie były.

Dobrym przykładem tego może być postrzeganie rodziny nie jako ważnego i pod wieloma względami niezastąpionego podmiotu społecznego, ale jako grupy stanowiącej bliżej nieokreśloną przestrzeń poddaną wyłącznie subiektywnym i zindywidualizowanym decyzjom jednostek - zarówno w odniesieniu do jej tworzenia, przekształcania, jak i rozwiązywania. Jest oczywiste, że w takiej perspektywie najbardziej poszkodowani są najsłabsi, którymi w tym wypadku zwykle są dzieci. Wobec takiego nieadekwatnego sposobu widzenia instytucji rodziny nie może dziwić, że kolejne pomysły na poprawę jej kondycji, czy chociażby losu samych dzieci, rzadko przynoszą pożądane efekty. Chodzi tu o to, że przez lata upierano się, aby nie przyjmować do wiadomości, że rozpad małżeństwa ma wielowymiarowe negatywne skutki przede wszystkim dla potomstwa, ale także dla dorosłych, a z konsekwencjami rozwodów - takimi jak wychowywanie się dziecka pod opieką samotnego rodzica - starano się radzić sobie poprzez uzupełnianie luk dochodowych. Obecnie - szczególnie wobec wyników badań takich autorów jak James J. Heckman czy Judith Wallerstein ${ }^{8}$ - nie da się dalej bronić tego rodzaju polityki społecznej, która po prostu okazuje się mało skuteczna. W zamian za to w literaturze - np. socjologicznej - pojawiały się propozycje, aby przyjąć taki stan rzeczy i raczej zająć swoje myślenie innymi - atrakcyjnymi z pozoru, lecz niewiele wnoszącymi intelektualnie - koncepcjami, jak płynna rzeczywistość (Bauman) czy czysta relacja (Giddens ${ }^{9}$ ).

8 Pierwszy ze wspomnianych autorów pokazuje w swych badaniach - za które uzyskał Nagrodę Banku Szwecji im. Alfreda Nobla w dziedzinie nauk ekonomicznych że dzieci wychowujące się i dorastające w niepełnych rodzinach ponoszą konkretne straty, jeśli chodzi o rozwój zarówno tzw. umiejętności niepoznawczych, jak i poznawczych. W rezultacie w porównaniu ze swymi rówieśnikami z pełnych rodzin mają mniejsze szanse na osiągnięcie w życiu sukcesów edukacyjnych i zawodowych. Z kolei druga autorka w wyniku wieloletnich badań wpływu rozwodów na życie dzieci wskazuje jednoznacznie na ich szkodliwość.

9 Por. A. Giddens, Nowoczesność i tożsamość. „Ja” i społeczeństwo w epoce późnej nowoczesności, tłum. A. Szulżycka, Wydawnictwo Naukowe PWN, Warszawa 2001, ss. $46-47$. 


\section{Poza alternatywą „kapitalizm-socjalizm" - w stronę perspektywy kulturowej}

Nieodłącznym elementem licznych dyskusji o gospodarce i ekonomii jest opozycja „kapitalizm-socjalizm”, stanowiąca zwykle kluczowy i dominujący punkt odniesienia dla ich uczestników. Być może właśnie dlatego tak często nie prowadzą one do jasnych i czytelnych konkluzji, a w rezultacie oponenci jedynie umacniają się we własnych poglądach i przekonaniach. W jakimś sensie dowodem na to może być fakt, że w dysputach czy to polityków, czy ekonomistów na temat właściwej polityki gospodarczej i społecznej argumentacja ogranicza się przeważnie do instrumentów czy rozwiązań natury ekonomicznej.

Biorąc pod uwagę ten problem, w niniejszym artykule postuluję konieczność wyjścia, po pierwsze, poza alternatywę „,kapitalizm-socjalizm”, a po drugie, na konieczność zwrócenia uwagi na podłoże kulturowe - rozumiane jako sfera norm, wartości i przekonań, które w sposób istotny wpływają na podejmowane decyzje i działania w ramach ładu społeczno-gospodarczego.

W tym zamierzeniu ważną inspirację znajduję w pracy Johna Larrivee, który w pracy pod znamiennym tytułem It's Not the Markets, It's the Morals: How Excessively Blaming Markets Undermines Civil Society, stwierdza, że:

skrajne ideologie dwudziestego wieku - komunizm, faszyzm i narodowy socjalizm - spowodowały totalitarną katastrofę wszędzie, gdziekolwiek zostały wdrożone. Co istotne, głównym powodem, dla którego tak wiele krajów eksperymentowało z tymi przerażającymi systemami, było to, że chciały one powstrzymać zło, o które oskarżano kapitalizm. To, że te eksperymenty nie powiodły się (przy okazji powodując o wiele więcej zniszczenia, niż rynki kiedykolwiek byłyby w stanie uczynić), sugeruje, że te ideologie zasadniczo błędnie zlokalizowały źródło problemów społecznych poprzez położenie zbyt dużego nacisku na czynniki ekonomiczne. To przypisywanie zbyt dużej wagi czynnikom ekonomicznym stanowiło jeden z głównych błędów dwudziestego stulecia ${ }^{10}$.

Uważam więc, że współczesne problemy są przede wszystkim natury kulturowej, a nie ekonomicznej, społecznej czy demograficznej. Oznacza to tyle, że nie da się ich zrozumieć i rozwiązać bez zagłębienia się w podłoże

10 J. Larrivee, It's Not the Markets, It's the Morals: How Excessively Blaming Markets Undermines Civil Society, w: T.E. Woods, Back on the Road to Serfdom. The Resurgence of Statism, ISI Books, Wilmington 2010, s. 131. 
aksjonormatywne, na którym ujawniają się określone postawy i działania. Wydaje się, że z taką intuicją swą propozycję kulturalizmu formułował Florian Znaniecki, który widząc z jednej strony redukcjonizm naturalizmu - przede wszystkim w wydaniu nauk przyrodniczych, a z drugiej - niemoc idealizmu, jaki zdominował filozofię, domagał się zasadniczej zmiany perspektywy ${ }^{11}$.

Warto więc spojrzeć na ten swoisty zwrot kulturowy jako na powrót do rzeczywistego obrazu osoby ludzkiej i społeczeństwa, które współtworzy. Oznaczałby on więc między innymi ponowne zwrócenie uwagi na wartości moralne, które stoją u podstaw ludzkiego myślenia i działania. Innymi słowy, chodzi o to, by ukazać błędność perspektywy koncentrującej się wyłącznie na aspektach materialnych i upatrującej rozwiązania problemów społecznych właśnie w zasobach materialnych, a zarazem podkreślić znaczenie czynników niematerialnych, które Larrivee określa mianem zasobów duchowych. W tym kontekście zasadne staje się mówienie o swoistej materialistycznej transformacji kultury Zachodu, czego dowodem w jakiś sposób jest paradoksalny pod wieloma względami powrót - w przeróżnych formach - marksizmu, który jest przecież w swej istocie materializmem. Innym przejawem tego może być wspomniana koncentracja na wymiarze ekonomicznym poprzez fundowanie dyskusji na tematy społeczne i cywilizacyjne tylko i wyłącznie na opozycji „kapitalizm-socjalizm”, poza którymi nie dostrzega się już istotniejszych kwestii.

W tym kontekście, aby właściwie zrozumieć aktualne problemy i móc poszukiwać ich rozwiązania, należy zwrócić uwagę na to, w jaki sposób zmieniła się kultura Zachodu nie tylko w ostatnich dekadach, ale i stuleciach. Nie sposób tego jednak dokonać w pełni w ramach jednego artykułu, dlatego pozwolę sobie skrótowo zasygnalizować kluczowe zjawiska i zagadnienia z tym związane.

\section{Zachód i jego materialistyczna przemiana - reformacja, sekularyzacja, totalitarne rewolucje, postmodernizacja}

W tym miejscu przedstawiam cztery zjawiska, które choć mogą wydawać się niekiedy bardzo odległe od siebie w czasie, to jednak mają wspólny materialistyczny mianownik. Uważam, że to one szczególnie przyczyniły się do tego, iż brakuje obecnie adekwatnych map, które odzwierciedlałyby

11 Por. F. Znaniecki, Rzeczywistość kulturowa, w: idem, Pisma filozoficzne, t. 2, Państwowe Wydawnictwo Naukowe, Warszawa 1991, ss. 482-484. 
rzeczywistość w jej pełni. Odpowiadają za to cztery wymienione w tytule tej części zjawiska, którymi są: reformacja, sekularyzacja, totalitarne rewolucje oraz postmodernizacja. Najogólniej można stwierdzić, że przyczyniły się one do dominacji materialistycznej wizji rzeczywistości, w której brak miejsca na wymiar metafizyczny. W ten sposób życie człowieka, który według źródłowego kanonu filozoficzno-teologicznego cywilizacji zachodniej jest bytem biologiczno-psychiczno-duchowym, zostało zredukowane do egzystencji biologiczno-psychicznej.

Pierwszy z tych wskazanych kroków ku materializmowi to reformacja. Chodzi tu przede wszystkim o tezę o predestynacji i ten jej element, który wskazuje na to, że oznaką błogosławieństwa Bożego jest powodzenie w pracy czy - ogólnie - w interesach. Jest oczywiste, że konsekwencją takiego postawienia sprawy musiało stać się skoncentrowanie uwagi ludzkiej na sprawach doczesnych, które odtąd miałyby rzekomo zaświadczać o kondycji ludzkiej duszy. Poza tym takie zalety jak pracowitość czy punktualność zostały podniesione do rangi cnoty, co musiało wpłynąć na kształt systemu moralnego zreformowanego Zachodu. Ważnym aspektem reformacji był także indywidualizm, który otrzymał żyzną glebę do rozwoju dzięki temu, że odtąd rola Kościoła - wcześniej stanowiącego ważną strukturę pośredniczącą i sferę odniesienia dla jednostkowych poczynań - została zasadniczo zredukowana. Do tego warto dodać prawo do autonomicznej interpretacji Pisma Świętego, które w praktyce prowadziło do relatywizacji prawd objawionych. W ten sposób wymiar religijny ulegał stopniowej prywatyzacji, co w rezultacie doprowadzić musiało do podważenia, a w końcu do zmarginalizowania uniwersalistycznej perspektywy metafizycznej.

W powyższym opisie wyraźnie widać, że nieuchronnym następstwem procesów zainicjowanych przez reformację była sekularyzacja, której dziś szczególnie doświadczają właśnie te społeczeństwa, które w przeszłości zaakceptowały argumentację reformacji i zdecydowały się zreorganizować ład społeczno-kulturowy według jej wskazań. Za ważny element sekularyzacji - którego nie wyodrębniam tutaj ze względu na ograniczone rozmiary artykułu - należy na pewno uznać projekt oświeceniowy, w którym wyraźnie da się zauważyć wysiłek wyjaśnienia i zorganizowania świata bez narzędzi metafizycznych. W jakimś sensie można to uznać za dokończenie rewolucji kartezjańskiej i ogłoszenie panowania religii rozumu ludzkiego.

Kolejne zjawiska, które można uznać za istotne etapy przeobrażania cywilizacji zachodniej w kierunku materialistycznym, to rewolucje totalitarne, do których zaliczam rewolucję francuską, bolszewicką oraz 
faszystowską. Za ich wspólny mianownik można uznać to, że jednakowo z podejrzliwością i wrogością podchodziły do religii i aktywnie starały się eliminować związane z nimi instytucje. Ponadto każda z nich wychodziła z założenia, że niezbędnym sposobem zmiany społecznej jest eksterminacja tych, którzy uznani zostali za hamujących marsz ludzkości ku „świetlanej przyszłości”. Ich celem był nowy ład społeczny, wyzwolony od „hipoteki metafizycznej”, dzięki czemu wtopiona w masę bezbronna jednostka miała stać się doskonale podatna na kształtowanie osobowości według wskazań tych, których rewolucja uznawała za nieomylnych. Co więcej, każda z tych rewolucji wychodziła z założenia, że ma monopol na prawdę i wiedzę, co dodatkowo stawiało autonomię jakiegokolwiek uniwersalnego i transcendentnego systemu przekonań pod znakiem zapytania.

Ostatnim z procesów, które wskazuję jako współodpowiedzialne za to, co określam mianem materialistycznej przemiany kultury Zachodu, jest postmodernizacja, którą interesująco analizował między innymi Ronald Inglehart. Spośród pięciu wskazywanych przez niego cech tego zjawiska dla niniejszych rozważań szczególnie ważne są dwie: (1) rosnący nacisk na wolność indywidualną i doświadczenie emocjonalne, odrzucenie wszystkich form zwierzchności; (2) spadek prestiżu nauki, technologii i racjonalności ${ }^{12}$. Oczywiście, należy dodać, że w procesach postmodernizacyjnych przejawiają się już wcześniej opisane tu zjawiska i niektóre ich elementy charakterystyczne. Takim, niewątpliwie ważnym, rysem postmodernizacji już wcześniej ukazanym jest indywidualizacja, która w tym wypadku wydaje się iść o wiele dalej, niż miało to miejsce wcześniej, gdyż oznacza, że za depozytariusza prawdy, a więc również źródło wiedzy na temat tego, co jest dobre, a co złe, uważa się samą jednostkę.

Co ciekawe, przy okazji okazuje się, że paradoksalnie, negujący to, co wspólnotowe, i stawiający jednostkę ponad społecznością indywidualizm, oraz negujący to, co osobowe, czyniący jednostkę w jakimś sensie zakładnikiem zbiorowości kolektywizm stanowią de facto różne odmiany materializmu. W obu tych przypadkach mamy do czynienia z tym, co określa się mianem kultu jednostki, tyle że w każdym z nich przejawia się on inaczej.

${ }^{12}$ Por. R. Inglehart, Modernization and Postmodernization, w: B.E. Brown (red.), Comparative Politics: Notes and Readings, Belmont, California, Thomson/Wadsworth 2006, ss. 67-70), cyt. za: M.A. Michalski, Postmodernizacja a etyka i kultura gospodarcza Zachodu. Przemiany rodziny i socjalizacji a edukacja moralna, „Prakseologia” 160/2018 (DOI: 10.7206/prak.0079-4872_2015_160_4). 
Obie te koncepcje w swej istocie stanowią zakwestionowanie wymiaru transcendentnego i poddając człowieka wyłącznie prawom i pomysłom ludzkim, pośrednio zamykają tym samym jego życie w wymiarze ziemskim. W taki sposób tłumaczy to Alexander Yakovlev, który pisze:

materializm nieuchronnie prowadzi do fetyszyzmu [...] umożliwiając wyeliminowanie problemu wyboru duchowego [moralnego], przez co usunięta zostaje osobista odpowiedzialność, grzech i zadośćuczynienie. Materializm rozbraja duchowo osobę ludzką, czyniąc ją podatną na manipulację ideologiczną ${ }^{13}$.

Zwrócenie uwagi na te kwestie jest o tyle ważne, że u swych źródeł cywilizacja zachodnia wychodziła z perspektyw transcendentnych, a zarazem personalistycznych, i to w znacznej mierze dzięki temu osiągnęła tak bezprecedensowy poziom rozwoju pod wieloma względami.

\section{Podsumowanie}

Nakierowanie rozważań na problem materialistycznej transformacji kultury Zachodu stanowi propozycję nowego podejścia do analizowania kondycji społeczno-kulturowej tej formacji cywilizacyjnej w obliczu swoistego impasu w przypadku od dawna toczonej dyskusji między zwolennikami kapitalizmu a zwolennikami socjalizmu. Oznacza to, że badania o nastawieniu kulturowym - w naszym przypadku skoncentrowane na analizie kultury gospodarczej - wciąż stanowią atrakcyjną i niedostatecznie angażowaną alternatywę. Jej potencjał - także nie zawsze dostrzegany i wykorzystywany - w zakresie zastosowanej tu analizy alternatywnych koncepcji przez pryzmat obecności w nich wątków materialistycznych wydaje się przydatny do diagnozowania aktualnego kształtu kultury, a w jej obrębie na przykład koncepcji ekonomicznych, dzięki czemu możliwe jest wyjaśnianie zjawisk i procesów dokonujących się w obrębie cywilizacji, np. gospodarczych, od innej, rzadziej stosowanej strony.

Wydaje mi się to o tyle istotne i aktualne, że z jednej strony wciąż nie dokonuje się spodziewany, np. po kryzysie finansowym z lat 2008-2009, zwrot społeczno-kulturowy (a więc również etyczny) w ekonomii i gospodarce, a z drugiej - materializm dostrzegalnie przejmuje coraz to nowe

${ }^{13}$ A. Yakovlev, The Fate of Marxism in Russia, New Haven: Yale University Press 1993, s. 15, cyt. za: J. Larrivee, op. cit., s. 146. 
obszary praktyki społecznej. Potwierdza to, jak sądzę, ogólna obserwacja cywilizacji zachodniej, której kondycja coraz bardziej odpowiada diagnozie sformułowanej przez Znanieckiego, kiedy pisał:

tak więc materializm, dając pozorne usprawiedliwienie teoretyczne wszelkiego rodzaju dążnościom zwierzęcym, stale działa przeciwko naszej cywilizacji i przeciwko kulturze w ogóle na każdym polu, na którym jego zasady są stosowane praktycznie. Wzniósł on sztandar, dokoła którego zbierają się i organizują te siły, które pchają ludzkość wstecz, do stanu dzikości. Nie stworzył on tych sił, lecz wyniósł je na powierzchnię życia społecznego z podziemi, w których się kryły, i dodał im odwagi do czynnego, nie tylko biernego przeciwstawiania się mocy twórczej ideałów kulturowych. Sam przez się nie wystarczyłby do zniszczenia dzieła cywilizacji lub nawet do powstrzymania jej postępu. Lecz wywołuje on w umysłach ludu niedowierzanie względem wartości tego dzieła i przygotowuje je do poddania się innym, bezpośrednio niszczącym wpływom ${ }^{14}$.

Jeśli rzeczywiście Znaniecki ma rację, to w interesie przyszłości i rozwoju cywilizacji zachodniej warto podjąć systematyczny i pogłębiony namysł nad wpływem światopoglądu materialistycznego na jej kulturę, której kondycja wydaje się alarmująca.

\section{Literatura}

Bell D., Kulturowe sprzeczności kapitalizmu, tłum. S. Amsterdamski, Wydawnictwo Naukowe PWN, Warszawa 1998.

Berger P.L., Rewolucja kapitalistyczna, tłum. Z. Simbierowicz, Oficyna Naukowa, Warszawa 1995.

Boulding K.E., Etyka i biznes, w: J. Grosfeld (red.), Ponad ekonomiq, PIW, Warszawa 1985.

Giddens A., Nowoczesność i tożsamość, „Ja” i społeczeństwo w epoce późnej nowoczesności, tłum. A. Szulżycka, Wydawnictwo Naukowe PWN, Warszawa 2001.

Kochanowicz J., Wprowadzenie, w: J. Kochanowicz, M. Marody (red.), Kultura i gospodarka, Wydawnictwo Naukowe Scholar, Warszawa 2010.

Lane R.E., The Loss of Happiness in Market Democracies, Yale University Press, New Haven 2000.

Larrivee J., It's Not the Markets, It's the Morals: How Excessively Blaming Markets Undermines Civil Society, w: T.E. Woods, Back on the Road to Serfdom. The Resurgence of Statism, ISI Books, Wilmington 2010.

Michalski M.A., Postmodernizacja a etyka i kultura gospodarcza Zachodu. Przemiany rodziny i socjalizacji a edukacja moralna, „Prakseologia” 160/2018 (DOI: 10.7206/ prak.0079-4872_2015_160_4).

${ }^{14}$ F. Znaniecki, Upadek cywilizacji zachodniej, w: idem, Pisma filozoficzne, t. 2, s. 1000 . 
Schumacher E.F., Guide for the Perplexed, Harper Perennial, New York-London-TorontoSydney 2004.

Zakaria F., Koniec hegemonii Ameryki, tłum. S. Kroszczyński, Media Lazar NADIR, Warszawa 2009.

Znaniecki F., Rzeczywistość kulturowa, w: idem, Pisma filozoficzne, t. 2, Państwowe Wydawnictwo Naukowe, Warszawa 1991.

Znaniecki F., Upadek cywilizacji zachodniej, w: idem, Pisma filozoficzne, t. 2, Państwowe Wydawnictwo Naukowe, Warszawa 1991. 